OR-16

\title{
SOME IMIDAZOLYL BENZAMIDES AS POTENT ANTIBACTERIAL AGENTS
}

\author{
C. R. Dhilna, ${ }^{1}$ S. M. Gopinath, ${ }^{1}$ Muthipeedika Nibin Joy ${ }^{2}$ \\ ${ }^{1}$ Department of Biotechnology, Acharya Institute of Technology, Acharya Dr. Sarvepalli \\ Radhakrishnan Road, Soldevanahalli, Bangalore, Karnataka-560107, India. \\ E-mail: dhilnarose15@gmail.com \\ ${ }^{2}$ InnovationCentre for Chemical and Pharmaceutical Technology, Ural Federal University, 19 Mira \\ St., Yekaterinburg, 620002, Russia.
}

\begin{abstract}
A series of imidazolyl benzamides containing urea has been efficiently synthesized and evaluated for their antibacterial properties. ${ }^{1}$. Some of the molecules exhibited promising antibacterial activity when compared to the reference standard, Ciprofloxacin (Fig. 1).
\end{abstract}

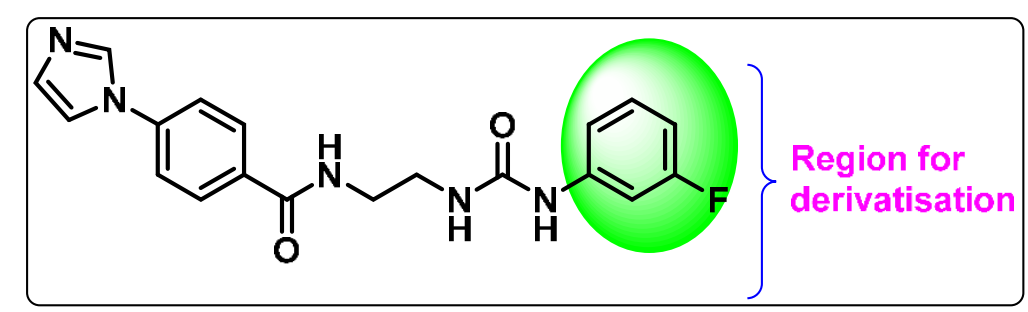

Figure 1:

General structure of imidazolyl benzamides

\section{References}

1. Kumar, S., Mukesh, K., Harjai,K., Singh,V. (2019).Synthesis of coumarin based Knoevenagel-Ugi adducts by a sequential one pot fivecomponent reaction and their biological evaluation as anti-bacterial agents.Tetrahedron Letters. Vol. 60, Iss. 1, pp. 8-12. 